\title{
A Rare Case of Ebstein Anomaly in a French Mastiff Dog
}

\author{
Saini Neetu ${ }^{1 *}$, Uppal Sanjeev Kumar ${ }^{1}$, Tandon Rohit ${ }^{2}$, Randhawa Sarnarinder Singh ${ }^{1}$ and Anand Arun ${ }^{3}$ \\ ${ }^{1}$ Department of Veterinary Medicine, Guru Angad Dev Veterinary \& Animal Sciences University, India \\ ${ }^{2}$ Non-Invasive Cardiology, Hero Heart Institute, Unit of Dayan and Medical College, India \\ ${ }^{3}$ Department of Veterinary Surgery and Radiology, Guru Angad Dev Veterinary \& Animal Sciences University, India
}

Submission: August 10, 2017; Published: August 24, 2017

*Corresponding author: Neetu Saini, Assistant Professor, Department of Veterinary Medicine, College of Veterinary Sciences, Guru Angad Dev Veterinary and Animal Sciences University (GADVASU), Ludhiana-141004, Punjab, India, Email: sainin26@gmail.com

\begin{abstract}
A one year old male French mastiff dog was presented with history of complete anorexia, ascites, exercise intolerance and lethargy. Chest radiographs revealed moderate to severe pleural effusions, tracheal elevation, increased tracheal bifurcation angle and pulmonary edema. Electrocardiography showed low voltage complexes and atrial fibrillation. Abdominal ultrasound revealed ascites and severe hepatomegaly. Haematobiochemical analysis revealed neutrophilic leukocytosis with mild thrombocytopenia and hypoproteinemia. Cytological and biochemical analysis of ascitic fluid indicated its modified transudate nature. Doppler echocardiography revealed tricuspid valve regurgitation with severe right atrial enlargement and there was downward displacement of tricuspid valve leaflets into the right ventricle indicating ebstein anomaly. The animal was treated with diuretics, vasodilators, ion tropic drugs for a period of four weeks. The patient died at home after four weeks of treatment and owner refused for postmortem examination.
\end{abstract}

Keywords: Ebstein anomaly; Dog; Echocardiography

\section{Introduction}

Tricuspid valve dysplasia (TVD) is a congenital deformity of tricuspid valve (TV), chordae tendineae, or papillary muscles resulting in insufficiency of tricuspid valve. The downward displacement of tricuspid valve leaflets into the right ventricle (RV) i.e. right ventricular atrialization results in a rare malformation called Ebstein's anomaly [1,2]. No doubt tricuspid valve dysplasia in dogs and cats are well mentioned in veterinary literature [3]. Ebstein anomaly is one of the rare forms of tricuspid valve dysplasia in dogs [4]. In present study, ebstein anomaly was detected in a young French mastiff dog.

\section{Case Report}

A one year old male French mastiff dog weighing 26kg was presented to Teaching Veterinary Hospital of Guru Angad Dev Veterinary \& Animal Sciences University (GADVASU) Ludhiana, Punjab in Northern India with history of complete anorexia, severe ascites, groaning, exercise intolerance and lethargy for the past one month. The owner has observed that the animal tries to vomit out i.e. gagging reflux for past one month. The vaccination and deworming status was complete. There was no history of fainting or weakness, syncope or seizures, coughing and lameness. Urine and fecal output was also normal.
The physical examination revealed pale mucous membrane, strong femoral pulse, normal rectal temperature (102으), jugular pulsation but no distension of jugular vein. Auscultation of chest revealed severe arrhythmia with grade IV systolic murmurs on right tricuspid valve area. The systolic blood pressure measured by Doppler method was $156 \mathrm{~mm}$ of Hg (Vet-dop2, Model BF2, Vmed technology, USA)

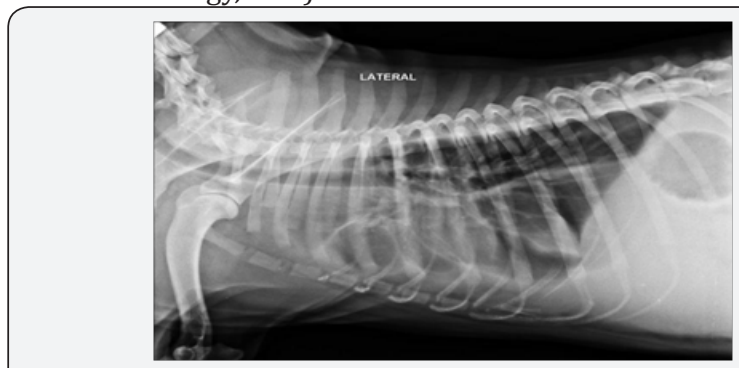

Figure 1a: Lateral chest radiographs revealed moderate to severe pleural effusions masking the cardiac shadow, tracheal elevation with increased tracheal bifurcation angle.

Lateral chest radiographs revealed moderate to severe pleural effusions masking the cardiac shadow and tracheal elevation. Left bronchus was pushed up dorsally and tracheal bifurcation angle was increased and pulmonary edema in caudal lung lobe. 
Ventrodorsal (VD) chest radiograph showed pleural effusions and right middle lung lobe showed severe congestion (Figure 1a \& 1b). The abdominal ultrasonography revealed severe ascites, extensively enlarged liver (hepatomegaly), covering almost the entire abdomen with mixed echotexture, thickened wall of gallbladder indicating cholecystitis. However spleen, kidney and urinary bladder were normal.

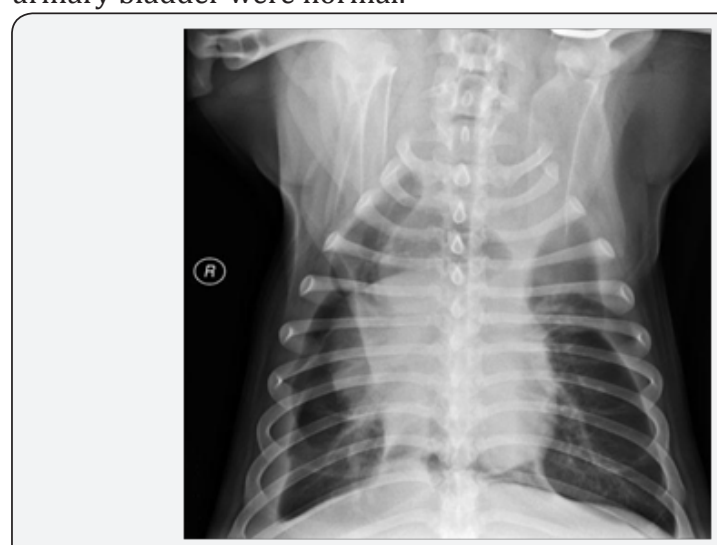

Figure 1b: Ventro-dorsal (VD) view showed pleural effusions and right middle lung lobe shows severe congestion.

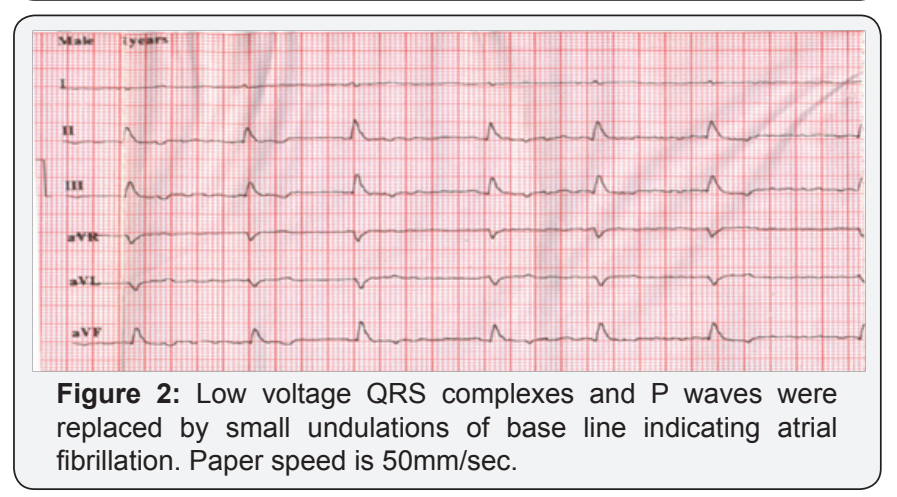

Electrocardiography (ECG) was performed by using Cardiart 8108 BPL six channel electrocardiographic machine with dog in right lateral recumbency. ECG examination revealed low voltage QRS complexes and P waves were replaced by small undulations of base line indicating atrial fibrillation. The $\mathrm{R}$ waves were $0.4 \mathrm{mV}$ (reference range: $2.5 \mathrm{mV}$ ) tall and 0.06 seconds (reference range: 0.05 seconds) wide indicating effusions in chest cavity (Figure 2). Heart rate was 107 beats per minute (reference: 70-160beats/ min.) with severe arrhythmia. Haematobiochemical analysis revealed neutrophilic leukocytosis, mild thrombocytopenia and hypoproteinemia. However, no changes were observed in rest of the parameters.

The ascitic fluid revealed numerous red blood cells, markedly degenerated neutrophils, few activated macrophages/mesothelial cells in small clumps and bacteria seen in background indicating chronic active peritonitis with focal adhesions. Biochemical analysis of ascitic fluid revealed total protein $4.4 \mathrm{~g} / \mathrm{dl}, \mathrm{pH}-8.5$, specific gravity 1.025 . Total cell count of ascitic fluid was $1570 /$ $\mathrm{mm} 3$. So on the basis of cytological and biochemical analysis, the nature of ascitic fluid was modified transudate.

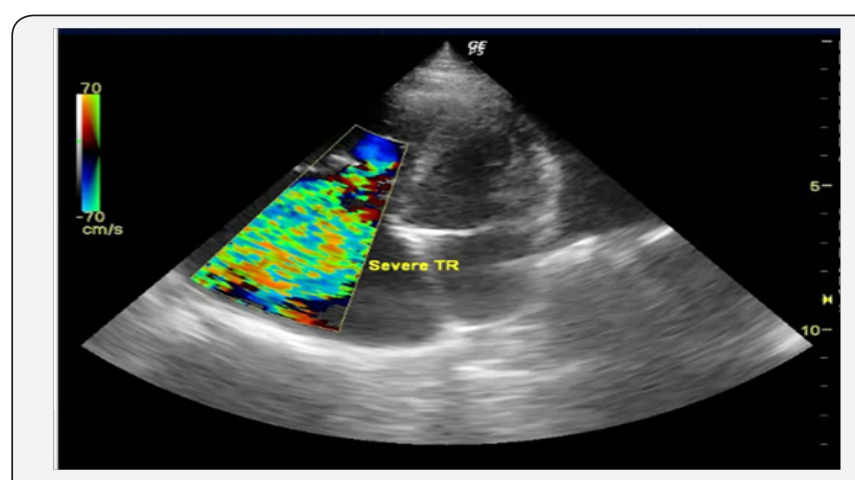

Figure 3a: Color doppler showing severe tricuspid regurgitation into right atrium in left apical four-chamber view.

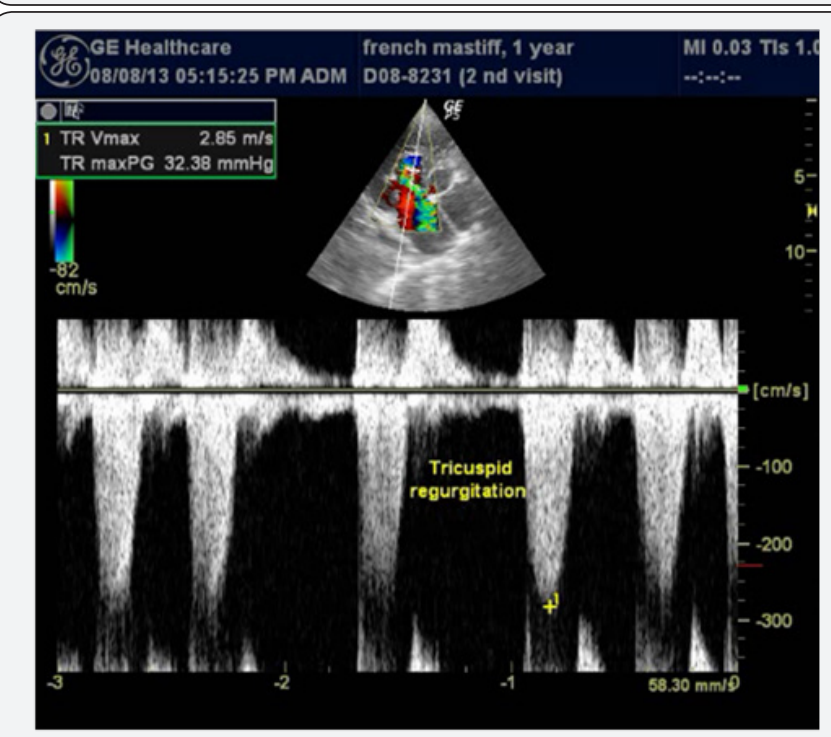

Figure 3b: Doppler echocardiography at tricuspid valve revealing turbulent jet flow with peak velocity of $2.85 \mathrm{~m} / \mathrm{s}$ indicating increased pressure gradient between the right atrium and right ventricle.

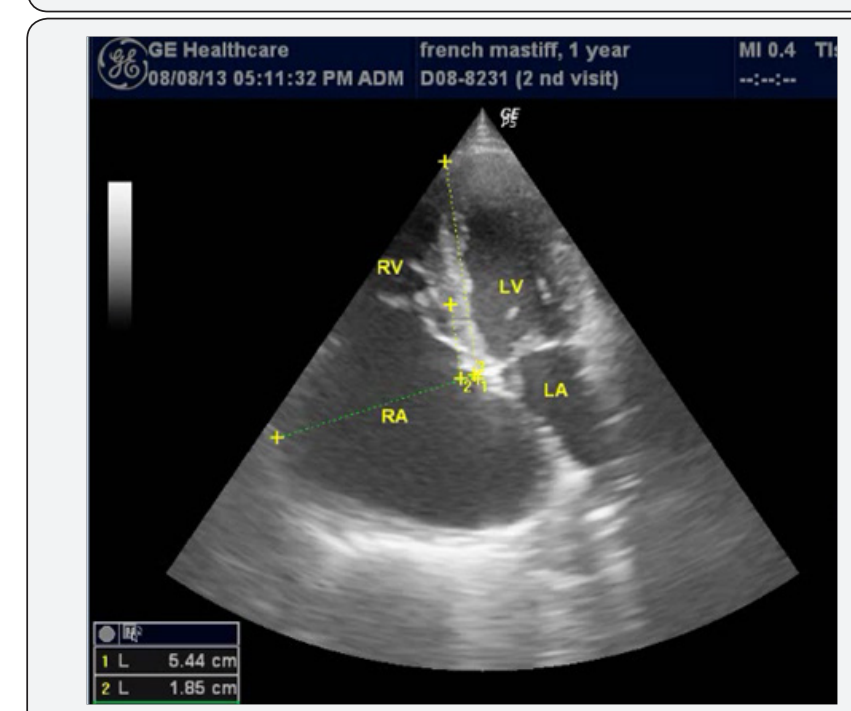

Figure 3c: The ventrally displaced tricuspid septal leaflet is seen in left apical 4 chamber view indicating Ebstein's anomaly. The total length of right ventricle was $5.44 \mathrm{~cm}$ with $1.85 \mathrm{~cm}$ atrialized right ventricle and $5.44-1.85=3.59 \mathrm{~cm}$ anatomical RV. Tricuspid valve annulus was $5.14 \mathrm{~cm}$ wide. 


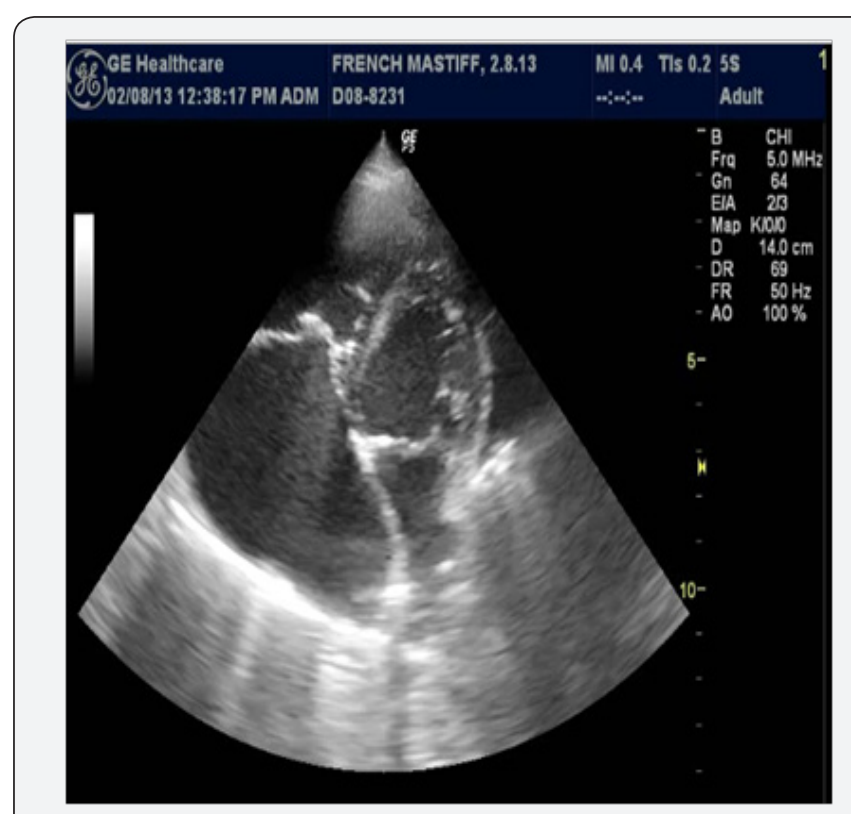

Figure 3d: The characteristic sail like deformity of displaced tricuspid apparatus in left apical four chamber view.

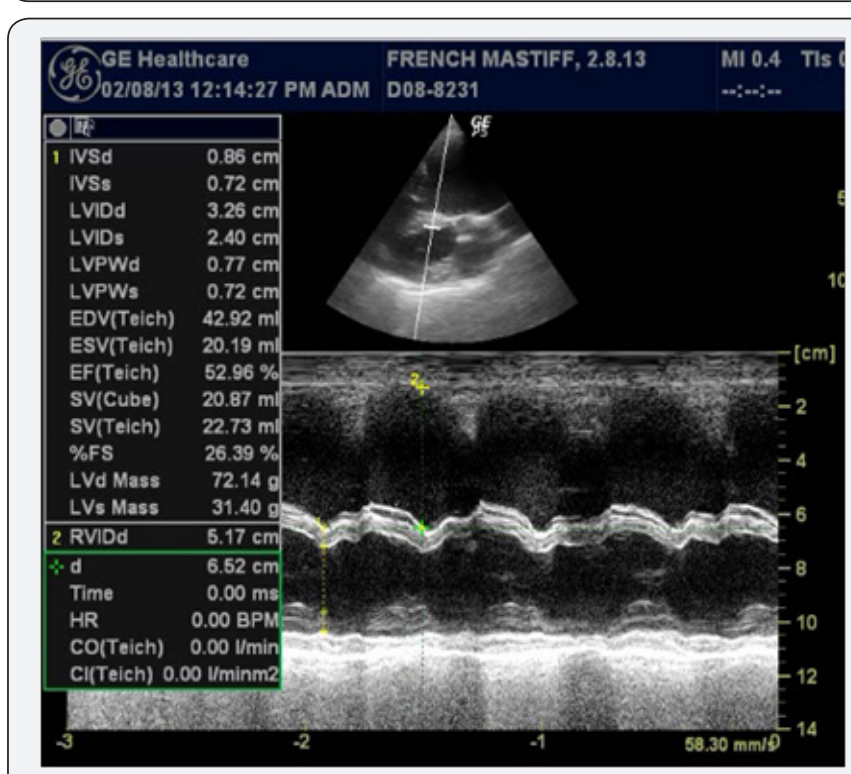

Figure 3e: M mode echocardiography showing normal Left ventricular functions and paradoxical movement of interventricular septum.

Two Dimensional, Mmode, Color flow doppler and Continuous wave doppler was performed by using GE Logiq P5 color Doppler ultrasound machine (GE healthcare, Chicago, United States) equipped with $5 \mathrm{~S}$ transducer. Two dimensional echocardiography with Color doppler at left apical four chamber view revealed severely enlarged right atrium with tricuspid regurgitation and displacement of tricuspid valve from anatomical annular position (Figure 3a). Continuous wave Doppler echocardiography over tricuspid valve revealed a turbulent regurgitant jet with peak velocity of $2.85 \mathrm{~m} / \mathrm{sec}$ (Figure $3 \mathrm{~b}$ ). Based upon the modified Bernoulli equation ( $\mathrm{P}=4 \mathrm{xvelocity} 2)$, the systolic pressure gradient between right ventricle and right atrium was $32.49 \mathrm{~mm}$ of $\mathrm{Hg}$. The total length of right ventricle was $5.44 \mathrm{~cm}$ with $1.85 \mathrm{~cm}$ atrialized right ventricle and $5.44-1.85=3.59 \mathrm{~cm}$ anatomical RV. The opening of tricuspid valve annulus was $5.14 \mathrm{~cm}$ wide (Figure 3c). The characteristic sail like deformity of displaced tricuspid apparatus could be well appreciated in apical four chamber view and can be morphologically explained by tethering of septal leaflet to interventricular septum and subsequent covering of tricuspid opening by anterior tricuspid leaflet to enhance coaptation (Figure 3d). M mode echocardiography at right parasternal short axis view indicated normal left ventricular functions and paradoxical interventricular septum. Fractional shortening (FS\%) and ejection fraction (EF\%) were within the normal range in the present case (Figure 3e). The animal was treated with Ampicillin @25mg/kg b.wt parenterally 12 hourly for 1 week, furosemide (@2mg/kg, po, q12h), Enalapril (0.5mg/ kg P0 every 12hr) with salt-restriction in diet. For atrial fibrillation, digoxin was given $@ 0.008 \mathrm{mg} / \mathrm{kg}$ b.wt. Four weeks after the treatment, the dog died at home and owner refused the necropsy.

\section{Discussion}

Congenital and secondary tricuspid valve abnormalities are rarely reported in dogs and cats [4-6]. The incidence of tricuspid valve dysplasia ranges from 7.0 to $7.5 \%$ out of all congenital heart defects occurring in dogs [6]. Large and pure breed dogs especially Labrador Retrievers, Boxers and German Shepherds are mostly affected [4]. Clinical signs of ascites, pleural effusions, weakness, lethargy, jugular vein pulsation and hepatomegaly suggested right sided heart failure in the present case $[4,6]$. Severe venous congestion in the right atrium might be responsible for occurrence of ascites and hepatomegaly [1]. Supraventricular tachycardia (SVT) is one of the common conduction abnormalities seen in human patients affected with ebstein anomaly [1]. In present case, atrial fibrillation and low voltage complexes were detected on electrocardiography without any evidence of right sided enlargement. Pleural effusions in this case might be responsible for low voltage complexes.

Echocardiography has been found be one of the best techniques for diagnosis of ebstein anomaly [7]. Echocardio graphically, ebstein anomaly was diagnosed on the basis of severely dilated right atrium, downward displacement of tricuspid valve leaflets into right ventricle leading to atrialization of right ventricle and severe tricuspid regurgitation [1].

A normal tricuspid valve leaflets attaches more apical than the anterior mitral leaflet in the 4-chamber view (1). However in present case tricuspid annulus was $1.85 \mathrm{~cm}$ lower than mitral annulus and tricuspid valve (TV) was displaced toward right ventricle (RV), resulting in RV atrialization leading to Ebstein's anomaly [1]. Echocardiographic evaluation mostly shows a markedly enlarged right atrium with right ventricular volume overload. Also, the left side of heart is mostly smaller than normal [5]. Similar findings were observed in the present study. On right parasternal short axis view, right ventricular volume overload resulted in paradoxical movement of the interventricular septum 
and an abnormally small left ventricle as seen in the present study [5].

Initially, to reduce the volume overload in the right heart chambers, diuretic (furosemide) and an angiotensin converting enzyme inhibitor (enalapril) was used. Diuretics, ACE inhibitors and positive inotropic drugs (digoxin) are indicated for the treatment of patients affected with ebstein anomaly [1]. Diuretics and an ACE inhibitor can improve the heart function by reducing cardiac workload and fluid volume in pleural space [8]. Digoxin reduces the activation of the sympathetic nervous system and renin-angiotensin-aldosterone system [9].

So in differential diagnosis of dogs with right-sided cardiomegaly, Ebstein's anomaly should always be included [10]. Echocardiographic criteria for this anomaly are right atrial enlargement, TV regurgitation and an abnormally downward displaced TV. So owner was informed that the prognosis is poor in spite of medical therapy. The prognosis of patients with Ebstein's anomaly varies considerably depending upon the severity of the tricuspid valve leaflet displacement and subsequent tricuspid valve regurgitation, severity of right side heart failure and conduction disturbances [11].

\section{References}

1. Shaughhnessy R (2004) Ebstein's anomaly. In: Crawford MH, DiMarco JP, Paulus WJ (Eds.), Cardiology. ( $2^{\text {nd }}$ edn), Tokyo Mosby, USA, pp. 13351342.

2. Kittleson M D (1998) Congenital abnormalities of the atrioventricular valves. In: Kittleson MD, Kienle RD (Eds.), Small animal cardiovascular medicine. Saint Louis Mosby, USA, pp. 273-281.
3. Andelfinger G, Wright KN, Lee HJ, Siemens LM, Benson DW (2003) Canine tricuspid valve malformation, a model of human Ebstein anomaly, maps to dog chromosome. J Med Genet 40(5): 320-324.

4. Urszula Pasławska, Agnieszka Noszczyk-nowak, Adrian Janiszewski, Jozef Nicpon (2013) Tricuspid dysplasia in dogs. Bull Vet Inst Pulawy 57: 123-126.

5. Sousa G, Gerardi DG, Alves RO, Camacho AA (2006) Tricuspid valve dysplasia and Ebstein's anomaly in dogs: case report. Arq Bras Med Vet Zootec 58(5): 762-767.

6. Tidholm A (1997) Retrospective study of congenital heart defects in 151 dogs. J Small Anim Pract 38(3): 94-98.

7. Ran Choi, Seung Keun Lee, Hyeong Sun Moon, In Chul Park, Changbaig Hyun (2009) Ebstein's anomaly with an atrial septal defect in a jindo dog. Can Vet J 50(4): 405-410.

8. Takemura N, Machida N, Nakagawa K, Hajime A, Makoto W, et al. (2003) Ebstein's anomaly in a beagle dog. Journal of Veteri Medical Science 65(4): 531-533.

9. Ferguson DW, Berg WJ, Sanders JS, Roach PJ, Kempf JS et al. (1989) Sympathoinhibitory responses to digitalis glycosides in heart failure patients. Direct evidence from sympathetic neural recordings. Circulation 80(1): 65-77.

10.Zeki Yilmaz, Pınar Levent, Mmeric Kocaturk, Huseyin Cihan, Elif pars, et al. (2015) Chylothorax associated with Ebstein's anomaly in a Golden Retriever dog. Ankara Univ Vet Fak Derg 62: 243-246.

11. Chetboul V, Tran D, Carlos C, Tessier D, Pouchelon JL (2004) Congenital malformations of the tricuspid valve in domestic carnivores: A retrospective study of 50 cases. Schweiz Arch Tierheilkd 146(6): 265275.

\begin{tabular}{l} 
Your next submission with Juniper Publishers \\
will reach you the below assets \\
- Quality Editorial service \\
- Swift Peer Review \\
- Reprints availability \\
- E-prints Service \\
- Manuscript Podcast for convenient understanding \\
- Global attainment for your research \\
- Manuscript accessibility in different formats \\
( Pdf, E-pub, Full Text, Audio) \\
- Unceasing customer service \\
Track the below URL for one-step submission \\
https://juniperpublishers.com/online-submission.php \\
\hline
\end{tabular}

